\title{
Event-Related Potential Correlates of the Retrieval of Emotional and Nonemotional Context
}

\author{
Adam P. R. Smith, Raymond J. Dolan, and Michael D. Rugg
}

\begin{abstract}
In two experiments, we examined event-related potentials (ERPs) elicited in an old/new recognition memory test by emotionally neutral visual objects that, at encoding, had been associated with neutrally, negatively, or positively valenced background contexts. In Experiment 2, subjects also judged the context in which the item had been studied. In Experiment 1, "left parietal" old/new ERP effects were elicited by correctly recognized items. Items encoded in emotional contexts, but not those studied in neutral contexts, elicited additional effects early in the recording epoch over lateral temporal scalp and,
\end{abstract}

\section{INTRODUCTION}

Memory is often enhanced for events or items that are emotionally significant (for a review, see Christianson, 1992). This observation raises the question as to the cognitive and neural mechanisms responsible for interactions between memory and emotion. One influential hypothesis is that the primary locus of these interactions is during consolidation of memories (Tabert et al., 2001; Adolphs, Tranel, \& Denburg, 2000; Cahill \& McGaugh, 1998). By this argument, the enhancing effects of emotion on memory emerge over time to render emotional memories more durable or accessible than nonemotional memories. The mechanisms underlying the retrieval of the emotional and nonemotional memories could, however, be equivalent. An alternative hypothesis argues that, regardless of any effects on consolidation, emotion also influences retrieval processes (Maratos, Dolan, Morris, Henson, \& Rugg, 2001; Dolan, Lane, Chua, \& Fletcher, 2000).

The studies of Maratos et al. (2001) and Dolan et al. (2000), which both employed functional neuroimaging methods (PET and fMRI, respectively), demonstrated that retrieval of emotional versus nonemotional information was associated with enhanced activity in brain regions and circuits held to be specialized for the processing of emotion (e.g., the amygdala). However, as was noted by Maratos et al., these findings are difficult

University College London later, over left temporo-frontal scalp. In Experiment 2, "left parietal" and "right frontal" ERP effects were elicited by recognized items that attracted correct source judgments. Additional effects, an early lateral temporal positivity and a late-onset, leftsided positivity, were elicited by items studied in emotionally valenced contexts and attracting correct source judgments. Together, the findings indicate that retrieval processing is influenced by the emotional valence of the context in which an item is encoded, regardless of whether contextual information is task relevant.

to interpret, in that it is unclear whether they indicate emotion modulated the initial retrieval of information from memory or its subsequent processing. This ambiguity arises because the temporal resolution of hemodynamic measures of neural activity is insufficient (even when employed in event-related fMRI designs, as in Maratos et al., 2001), to accurately assess the time course of item-related memory effects.

Event-related potentials (ERPs) provide an alternative method for investigating the neural correlates of emotion versus emotional memory retrieval. Although lacking the spatial resolution of hemodynamic methods, ERPs have the benefit of high temporal resolution. Thus, they are well suited to investigating the time course of the effects of emotion of memory retrieval. Specifically, it is possible to ask whether these effects emerge at the same time as effects that index successful retrieval. If emotion and retrieval effects onset together, this would constitute evidence for an effect of emotion on retrieval per se. Alternatively, the finding that emotion effects lag behind those of retrieval would be consistent with a "postretrieval" locus; that is, it would suggest that emotion modulates processes operating on the products of retrieval rather than the initial recovery of information from memory.

The ERP correlates of retrieval processing have been investigated by comparing the waveforms elicited by correctly classified old and new items during recognition memory tasks. A number of characteristic "old/new" ERP memory effects have been identified in such studies, which appear to correlate with different components of 
retrieval processing (see Friedman \& Johnson, 2000; Rugg \& Allan, 2000, for reviews). One effect relevant to the present study is a positivity with a left parietal maximum - the so-called left parietal old/new effect. This effect onsets around $400 \mathrm{msec}$ poststimulus, has a duration of around $500 \mathrm{msec}$, and is thought be a correlate of episodic retrieval or "recollection" (Rugg, Schloerscheidt, Doyle, Cox, \& Patching, 1996; Smith, 1993). A second relevant effect is the "right frontal old/new effect." As its name implies, this is maximal over the right frontal scalp and onsets around 500-600 msec poststimulus, persisting for a second or more. The effect has been proposed as a neural correlate of postretrieval monitoring (Rugg et al., 1998; Wilding \& Rugg, 1996).

The present experiment was motivated by a previous ERP study of the retrieval of emotional information. In two experiments, Maratos and Rugg (2001) investigated the ERPs associated with the recognition of emotionally neutral words, which had been presented in emotionally neutral or negative sentences. ${ }^{1}$ In Experiment 1 , the test task was old/new recognition. Words encoded in negative sentences elicited larger "left parietal" ERP effects than those encoded in neutral sentences and, in addition, elicited a prominent right frontal effect. Because the effects of emotion in this experiment took the form of modulations of old/new effects common to emotional and nonemotional material, Maratos and Rugg concluded that the findings provided no evidence to suggest that the retrieval of emotional and nonemotional information engaged distinct neural systems.

In their second experiment, Maratos and Rugg (2001) required subjects to make both recognition and source judgments, explicitly discriminating between words that had been encoded in negative versus neutral sentences. In contrast with the findings of their first experiment, there were now no effects of emotion on either left parietal or right frontal effects, which were large and robust for all correctly recognized words. In light of these findings, Maratos and Rugg interpreted the results of their first experiment as evidence that contextual information is more likely to be retrieved incidentally, and to capture attention, when it is emotionally valenced.

The present study extends that of Maratos and Rugg (2001) by employing pictorial material and investigating the effects of positively as well as negatively valenced contexts. Pictorial stimuli are likely to be more effective at engaging emotional processing than verbal stimuli because of their highly concrete nature and "cognitive immediacy." The use of pictures to provide emotionally valenced contexts may, therefore, lend greater power to the identification of emotion effects on retrieval processing than was afforded by the verbal stimuli employed by Maratos and Rugg. Furthermore, the employment of positive as well as negative contexts allows a distinction to be drawn between valence-specific and -independent emotion effects, unlike in the previous study. As in that study, we investigated whether the effects of emotional versus neutral contexts were evident in a test of simple recognition memory and in a source memory task.

\section{EXPERIMENT 1}

\section{Results}

\section{Behavioral Data}

Mean $(S D)$ valence ratings for each class of background were neutral: 0.091 (0.46), positive: 1.21 (0.61), and negative: -1.45 (0.64). Ratings for both positive and negative backgrounds differed significantly from neutral background ratings (both $F>100, p<.001$ ). The difference in mean ratings between negative and neutral backgrounds was greater than that between positive and neutral backgrounds, $F(1,17)=44.5, p<.001$.

Mean accuracy and reaction time (RT) at test are shown in Table 1. One-way ANOVA of hit rates showed a main effect of condition, $F(1.6,26.7)=3.85, p<.05$ (here and in all subsequent ANOVAs, degrees of freedom are adjusted with the Greenhouse-Geisser correction for nonsphericity). Planned $t$ tests were employed to test the prediction (see Introduction) that hit rates for items paired with negatively ("negative hits") and positively ("positive hits") valenced backgrounds would exceed the rate for those paired with neutral backgrounds ("neutral hits"). The tests revealed a reliable difference between positive and neutral hit rates, $t(17)=3.64, p<.05$, but not between negative and neutral hit rates $(p>.5)$. A Tukey HSD test revealed that the difference between positive and negative hit rates was marginally significant $(p<.06)$. An ANOVA on hit RTs revealed no significant effect.

\section{Event-Related Potential Data}

The mean (range) number of trials contributing to the average ERPs for each response type were correct rejections, 41 (20-82); neutral hits, 23 (16-57); negative hits, 24 (16-51); and positive hits, 23 (16-41). For the reasons given below, the waveforms for the negative and positive hits were collapsed to form a single "emotional hit" condition. The grand average waveforms for selected electrode sites are shown in Figure 1.

As is evident from Figure 1, ERPs diverge as a function of condition from around $300 \mathrm{msec}$ poststimulus. Both types of old items elicited a positivity relative to the new items, which demonstrated an asymmetry in favor of the left hemisphere over the posterior scalp. This old/new effect persisted until around $1100 \mathrm{msec}$ in the ERPs to

Table 1. Mean $(S D)$ Accuracies and RTs for Experiment 1

\begin{tabular}{lcccc}
\hline & Neutral & Negative & Positive & New \\
\hline $\begin{array}{l}\text { Recognition } \\
\text { accuracy }\end{array}$ & $0.80(0.09)$ & $0.81(0.09)$ & $0.85(0.09)$ & $0.92(0.05)$ \\
\begin{tabular}{l} 
RT (msec) \\
\hline
\end{tabular} & $964(312)$ & $977(399)$ & $953(277)$ & $1069(293)$ \\
\hline
\end{tabular}


Figure 1. Grand average ERP waveforms elicited by correctly classified items in Experiment 1. Negative and positive hits have been collapsed into a single set of waveforms. Sites as depicted on the insert.

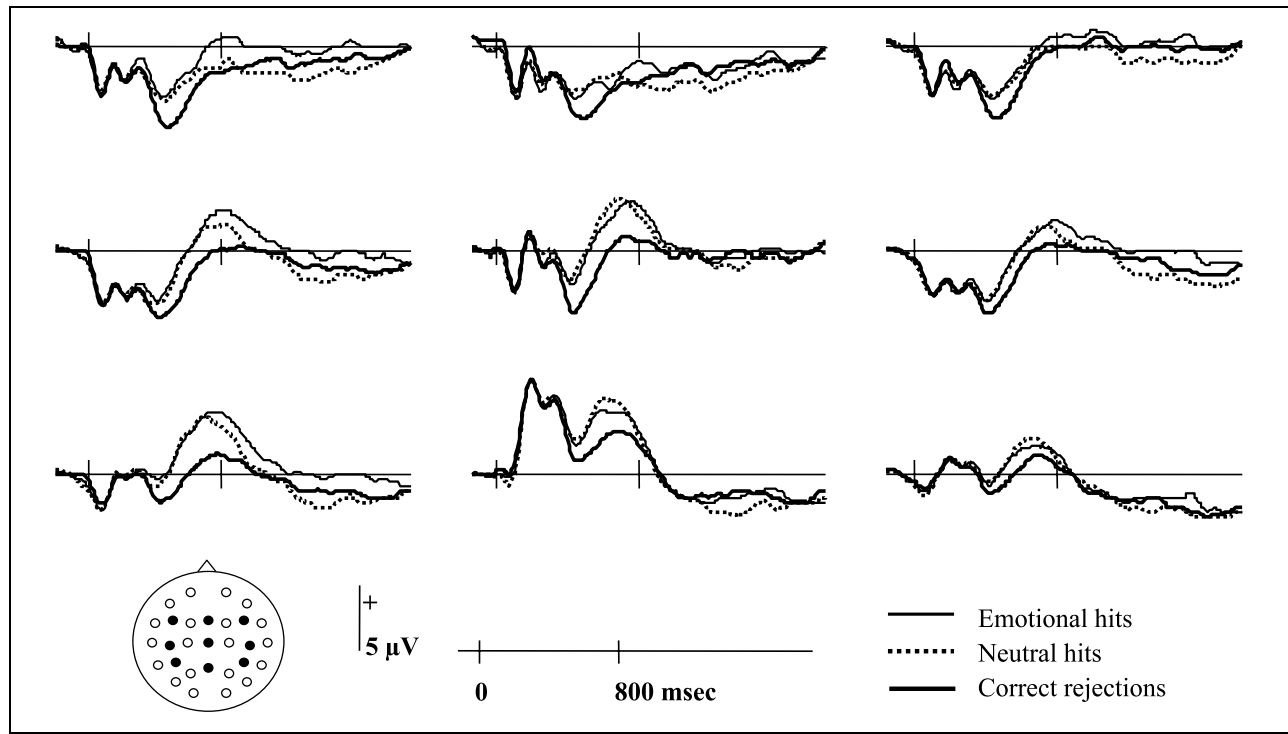

neutral hits. From around 700 msec the ERPs for emotional hits appear to contain an additional positive-going effect. This is most marked at midlateral sites, where it persists until the end of the recording epoch.

ERPs were quantified by measuring the mean amplitude of 5 consecutive latency regions (300-500, 500-800, 800-1100, 1100-1400, and 1400-1900 msec). These regions were selected based on the timing of memory effects in previous studies (e.g., Maratos \& Rugg, 2001; see also Rugg \& Allan, 2000) and visual inspection of the present data. Analyses of the ERP data proceeded in several stages. Preliminary analyses demonstrated that the ERPs elicited by the two classes of emotional hit did not differ reliably in any latency range (minimum $p>$ .1); thus, the data for these two item types were collapsed prior to the analyses presented below. To assess the effects of item type on ERP amplitude for each latency region, ANOVAs were performed on the data obtained from the electrode sites indicated in Figure 2. These ANOVAs were factored according to item type (correct rejection, neutral, and emotional), hemisphere, anteroposterior (AP) position (frontal, central/temporal, parietal), and lateral site (inferior, middle, superior). For any ANOVA that demonstrated a significant effect involving item type (effects that excluded item type are not reported in either these or follow-up ANOVAs), three subsidiary analyses were conducted to contrast separately neutral hits versus correct rejections (neutral old/new effects), emotional hits versus correct rejections (emotional old/new effects), and emotional hits versus neutral hits (emotion effects).

A second set of analyses contrasted the scalp topographies of the aforementioned ERP effects. To assess whether the topography of the neutral and emotional old/new effects differed, these were contrasted within all the latency regions in which the effects were independently significant, using the data from all 29 electrode sites. This ANOVA was conducted on difference scores (hit-correct rejection) after normalization with respect to range to obviate the confounding effects of global amplitude differences (McCarthy \& Wood, 1985). Factors were item type (neutral vs. emotional), latency region, and electrode site. A separate analysis, conducted along similar lines, contrasted the topography of the emotion effects within each of the regions in which they were significant.

\section{Mean Amplitude Analyses}

The outcomes of the overall ANOVAs are shown in Table 2 for each latency region. It can be seen that in

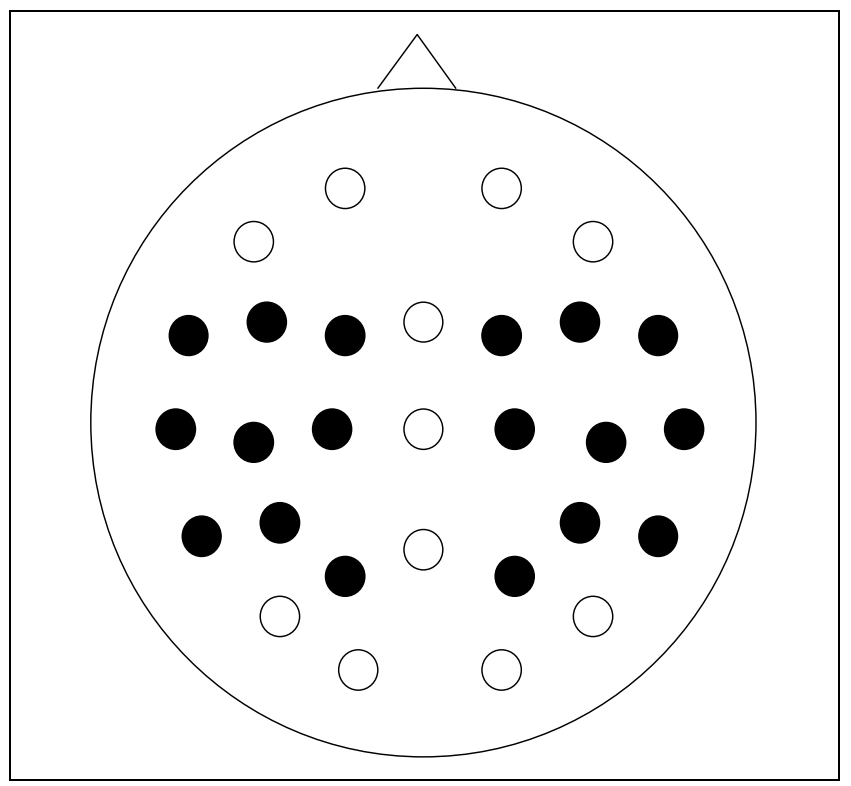

Figure 2. Electrode montage and the sites employed for amplitude analyses (black in-fills). 
each case, reliable effects involving the factor of item type were present. Also shown in the table are the results of the subsidiary ANOVAs for each latency range. We elucidate these below, discussing the neutral old/ new effects, emotional old/new effects, and emotion effects, respectively.

Neutral old/new effects. As shown in Table 2, a main effect of item type was found for the first three latency regions, reflecting in each case the greater positivity of ERPs to neutral hits. In the 500- to 800-msec region-when these old/new effects were at their maximum-item type interacted with hemisphere, reflecting the greater size of the old/new effects over the left hemisphere.

Emotional old/new effects. Emotional old/new effects were reliable in every latency region analyzed (Table 2), reflecting greater positivity for emotional hits. The in- teraction of these effects with hemisphere in the 500to $800-\mathrm{msec}$ and 800 - to $1100-\mathrm{msec}$ regions reflected the left-sided preponderance of the effects in this part of the epoch.

Effects of emotion. Table 2 also shows the outcomes of the contrasts between emotional and neutral hits. The first difference between the two classes of ERP emerged in the 300- to 500-msec latency range, in the form of a reliable interaction among item type, hemisphere, AP position, and lateral site. This interaction reflected a small positive shift in waveforms elicited in the emotional condition, clearest over right lateral posterior temporal scalp. Greater differences in amplitude emerge from $800 \mathrm{msec}$, after which the waveforms continue to differ until the end of the recording epoch. These differences were larger over the left than the right hemisphere in the 800- to 1100-msec and 1100- to 1400-msec latency regions, as evidenced by reliable interactions between

Table 2. $F$ values, Degrees of Freedom, and Probabilities Associated with Main Effects and Interactions at the Lateral Electrode Sites Indicated in Figure 2 for the Five Examined Latency Regions in Experiment 1

\begin{tabular}{|c|c|c|c|c|c|}
\hline Latency Region & $300-500 \mathrm{msec}$ & $500-800 \mathrm{msec}$ & $800-1100 \mathrm{msec}$ & $1100-1400 \mathrm{msec}$ & $1400-1900 \mathrm{msec}$ \\
\hline \multicolumn{6}{|l|}{ All hits versus $C R$} \\
\hline IT & $\begin{array}{c}F(1.8,31.2)=5.57 \\
p<.05\end{array}$ & $\begin{array}{c}F(1.7,28.3)=19.91 \\
p<.001\end{array}$ & $\begin{array}{c}F(1.7,29.3)=12.68 \\
p<.001\end{array}$ & $\begin{array}{c}F(1.6,27.8)=14.29 \\
p<.001\end{array}$ & $\begin{array}{c}F(1.5,25)=15.57 \\
p<.001\end{array}$ \\
\hline $\mathrm{IT} \times \mathrm{HM}$ & - & $\begin{array}{c}F(1.5,26.2)=7.33 \\
p=.005\end{array}$ & $\begin{array}{c}F(1.9,32)=3.70 \\
p<.05\end{array}$ & - & - \\
\hline $\mathrm{IT} \times \mathrm{AP}$ & - & - & $\begin{array}{c}F(2.4,41.5)=4.65 \\
p<.05\end{array}$ & - & - \\
\hline \multicolumn{6}{|l|}{ Neutral hit versus $C R$} \\
\hline IT & $\begin{array}{c}F(1,17)=7.13 \\
p<.05\end{array}$ & $\begin{array}{c}F(1,17)=19.88 \\
p<.001\end{array}$ & $\begin{array}{c}F(1,17)=4.78 \\
p<.05\end{array}$ & - & - \\
\hline $\mathrm{IT} \times \mathrm{HM}$ & - & $\begin{array}{c}F(1,17)=10.35 \\
p=.005\end{array}$ & - & - & - \\
\hline \multicolumn{6}{|c|}{ Emotional bit versus $C R$} \\
\hline IT & $\begin{array}{c}F(1,17)=10.21 \\
p<.01\end{array}$ & $\begin{array}{c}F(1,17)=22.00 \\
p<.001\end{array}$ & $\begin{array}{c}F(1,17)=22.19 \\
p<.001\end{array}$ & $\begin{array}{c}F(1,17)=9.42 \\
p<.01\end{array}$ & $\begin{array}{c}F(1,17)=12.1 \\
p<.005\end{array}$ \\
\hline $\mathrm{IT} \times \mathrm{HM}$ & - & $\begin{array}{c}F(1,17)=13.54 \\
p<.005\end{array}$ & $\begin{array}{c}F(1,17)=8.06 \\
p<.05\end{array}$ & - & - \\
\hline \multicolumn{6}{|c|}{ Emotional versus neutral bits } \\
\hline IT & - & - & $\begin{array}{c}F(1,17)=11.08 \\
p<.005\end{array}$ & $\begin{array}{c}F(1,17)=2.09 \\
p<.001\end{array}$ & $\begin{array}{c}F(1,17)=22.02 \\
p<.001\end{array}$ \\
\hline $\mathrm{IT} \times \mathrm{HM}$ & - & - & $\begin{array}{c}F(1,17)=4.475 \\
p=.05\end{array}$ & $\begin{array}{c}F(1,17)=4.483 \\
p=.05\end{array}$ & - \\
\hline $\mathrm{IT} \times \mathrm{AP}$ & - & - & $\begin{array}{c}F(1.2,20.1)=7.13 \\
p<.05\end{array}$ & - & - \\
\hline $\mathrm{IT} \times \mathrm{HM} \times \mathrm{AP} \times \mathrm{ST}$ & $\begin{array}{c}F(2.9,49.4)=3.041 \\
p<.05\end{array}$ & - & - & - & - \\
\hline
\end{tabular}

$\mathrm{IT}=$ item type; $\mathrm{HM}=$ hemisphere; $\mathrm{AP}=$ anteroposterior position; $\mathrm{ST}=$ lateral site. 
item type and hemisphere. In the earlier of these regions, an interaction with the factor of AP location indicated the emotion effects were greater over anterior scalp regions.

\section{Topographic Analyses}

The ANOVA contrasting the scalp distributions of the neutral and emotional old/new effects was conducted on data from the earliest three latency regions, when the effects were reliable for both effect types. A subset of these distributions is illustrated in Figure 3. The ANOVA revealed an interaction among latency region, effect type, and site, $F(7,118.4)=2.88, p<.01$, indicating that the scalp topographies of the two old/new effects changed differentially with time. Subsidiary ANOVAs, conducted on the data from each latency region separately indicated that the topographies of the effects did not differ reliably in the earliest two regions, but did so in the 800- to 1100-msec region, $F(4.6,78.6)=3.06, p<.05$.

The scalp topographies of the emotion effects (i.e., the differences between emotional and neutral hits) are illustrated in Figure 4 for the three latency regions in which they were reliable (800-1100, 1100-1400, and 1400-1900 msec). ANOVA revealed a significant Latency Region $\times$ Site interaction, $F(5.2,88.5)=2.72$, $p<.05$, reflecting the transition from a distribution that is initially maximal over the frontal and left temporal scalp to one more diffusely distributed over the lateral scalp.

\section{Discussion}

\section{Behavioral Data}

Items associated with positive contexts were recognized at a slightly, but significantly, higher level of accuracy than items encoded in either neutral or negative contexts. This result supports previous findings indicating that emotion can modulate recognition memory (e.g., Tabert et al., 2001), but suggests that such effects are subtle. The difference in recognition accuracy between items associated with positive and negative valences was not predicted, and we return to this finding in the general discussion.

\section{Event-Related Potential Data}

In line with many earlier reports (see Rugg \& Allan, 2000), correctly recognized items elicited ERPs that were more positive than those elicited by correctly rejected new items. This difference was evident from around $300 \mathrm{msec}$ poststimulus and, from around $500 \mathrm{msec}$, displayed the posterior asymmetry characteristic of the left parietal old/new effect (see Introduction). In contrast with a previous study (Maratos \& Rugg, 2001), this effect was not enhanced for recognized items that had been encoded in emotional as opposed to neutral contexts. On the assumption that the left parietal effect is a neural correlate of episodic retrieval ("recollection"; for reviews, see Friedman \& Johnson, 2000; Rugg \& Allan, 2000), this finding
Figure 3. Spherical spline maps showing scalp distributions of the old/new effects associated with recognition of items encoded in neutrally (A) and emotionally (B) valenced contexts in the latency regions (from left to right) 300-800, 800-1100, and 1100-1900 msec poststimulus. Each map is proportionately scaled between the extremes of the depicted effect (values in each case are given in microvolts).

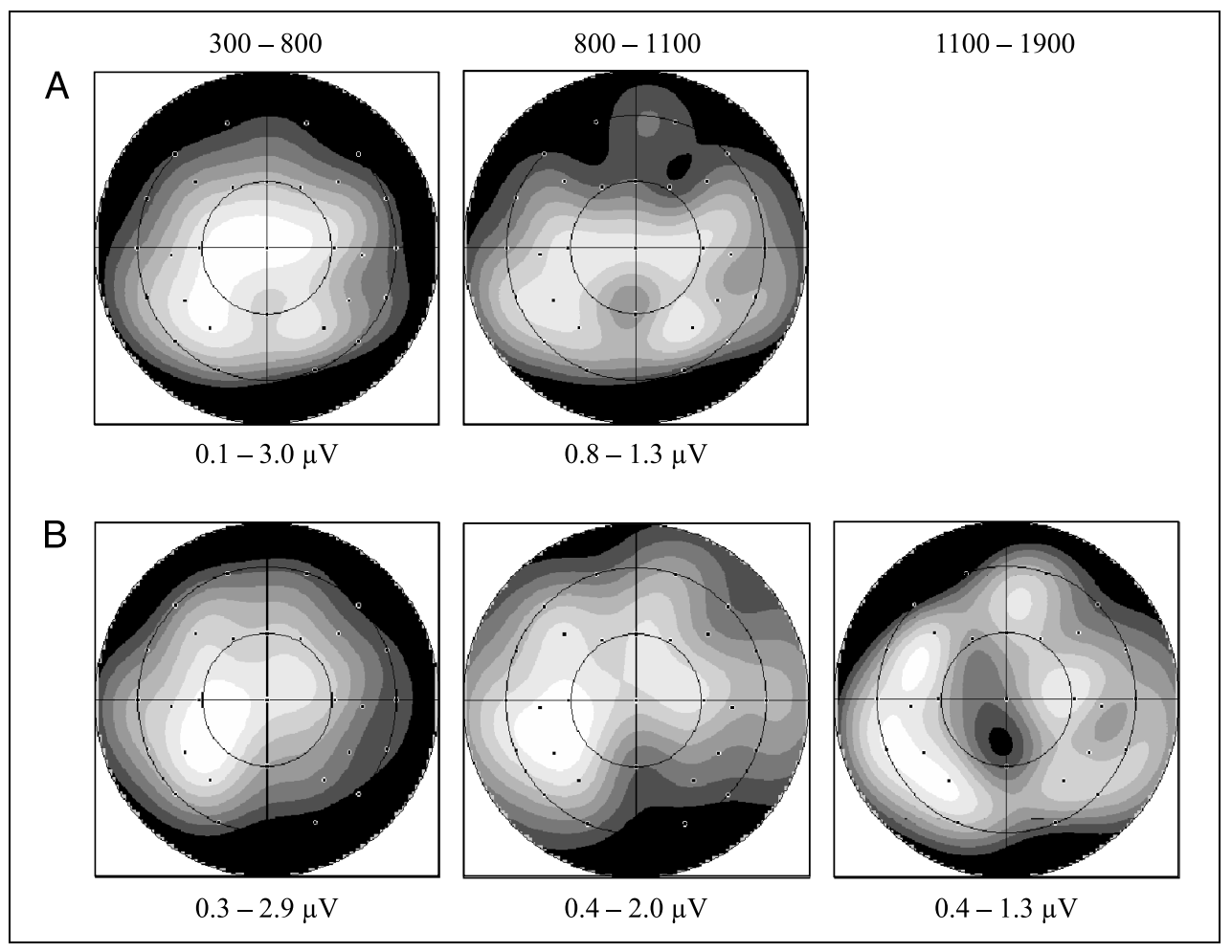


Figure 4. Spherical spline maps showing the scalp distributions of the emotion effect from Experiment 1 in the latency regions shown. Each map is proportionately scaled between the extremes of the depicted effect (values in each case are given in microvolts).

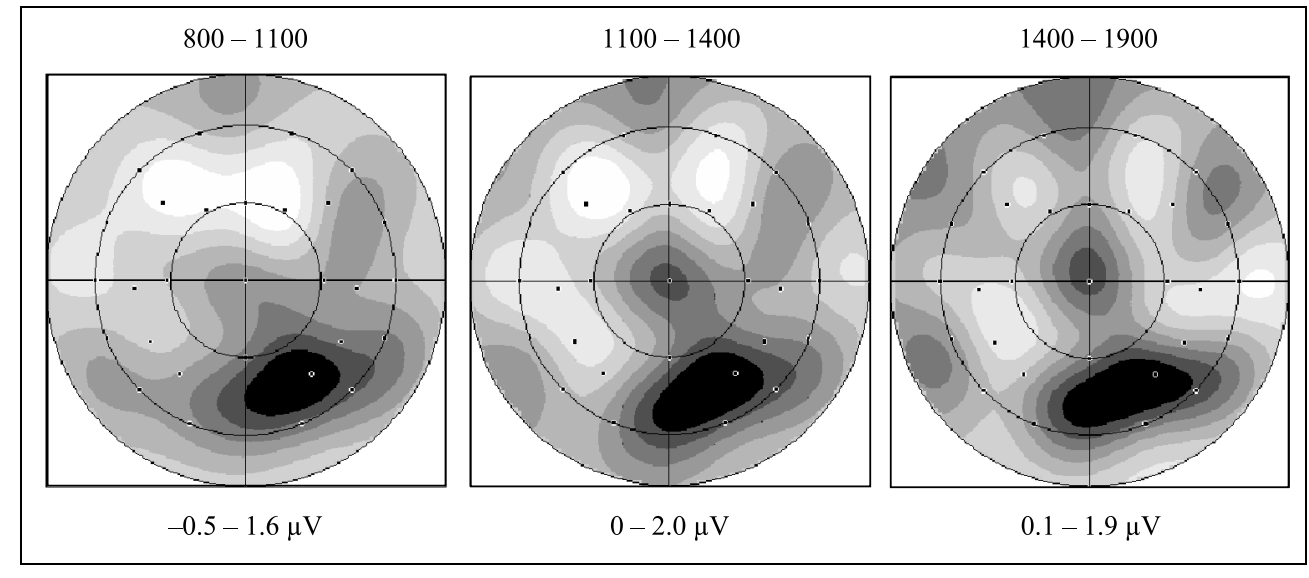

suggests that, unlike in the previous study, emotion influenced neither the probability of successful recollection nor the amount of episodic information that was retrieved. In the present experiment, the most evident ERP effects of emotion emerged around $800 \mathrm{msec}$ poststimulus, some $500 \mathrm{msec}$ after the onset of the aforementioned old/new effects. The relatively late onset of these emotion effects suggests that they reflect an emotional modulation of "postretrieval" processing, rather than processes directly affecting retrieval per se (see Introduction). In addition, an effect of emotion was present early in the recording epoch, with an onset around $300 \mathrm{msec}$ poststimulus. This effect was, however, small in amplitude and subsidiary analyses of data from the electrode sites where the effect was greatest gave rise only to weakly significant effects. We defer further discussion of these early effects until Experiment 2.

The present emotional old/new effects had scalp distributions supporting the presence of activity additional to that reflected by neutral old/new effects. This finding suggests that additional neural populations, and hence cognitive processes, were engaged by the retrieval of emotional relative to neutral material. The present findings differ from those of Maratos and Rugg's (2001) Experiment 1 in three important respects. First, as already noted, the manipulation of emotional context failed in the present case to influence the amplitude of the left parietal old/new effect. Second, this manipulation modulated the so-called right frontal effect only weakly at best (see Figure 3). Third, the principal effects of emotion were manifest in a pattern of a late ERP modulation that does not appear to resemble previously reported ERP old/new effects, raising the possibility of the engagement of emotion-specific (postretrieval) processing.

Several other studies utilizing pictures from the International Affective Pictorial System (IAPS) set (from which the majority of our contexts were drawn) have reported a "late positive potential" (LPP) ERP effect, which differentiates emotional from neutral pictures during either their active evaluation (e.g., Schupp et al.,
2000; Cacioppo, Crites, \& Gardner, 1996), active encoding (e.g., Dolcos \& Cabeza, 2002), or passive viewing (e.g., Keil et al., 2002). The amplitude of this effect was reported to be correlated with both arousal ratings and magnitude of galvanic skin response (Cuthbert, Schupp, Bradley, Birbaumer, \& Lang, 2000), but not with valence (negative vs. positive). It has been proposed that the LPP reflects motivational engagement and commitment of attentional resources to the processing of affective material (Lang, Bradley, \& Cuthbert, 1997; cf. Cuthbert et al., 2000; Schupp et al., 2000). Thus, one explanation for the late-onset emotion effect observed in the present experiment is that it reflects the engagement of similar processes, but in response to information retrieved from memory rather than present in the external environment. The onset of the emotion effects in the present experiment (ca. $700 \mathrm{msec}$ ) was somewhat later than the onset of the effects reported in the studies cited above (ca. $400 \mathrm{msec}$ ). Presumably, this is a consequence of the difference in the time required to respond to emotionally valenced information available directly from the environment, as opposed to information available only indirectly in the form of retrieved episodic information.

As in Experiment 1 of Maratos and Rugg (2001), the effects of emotion in the present experiment were observed in a yes/no recognition task in which the explicit retrieval and identification of the study context was unnecessary. Thus, the effects of emotion were presumably a consequence of the incidental retrieval and subsequent processing of contextual information. This raises the possibility that these effects reflect the engagement of emotionally nonspecific processes that are more easily triggered by task-irrelevant episodic information when it is highly salient than when it is not. To investigate this possibility, we conducted a further study in which the retrieval task was modified to necessitate the explicit retrieval of study context. If the present emotion effects merely reflect the greater salience of incidentally retrieved emotional contexts, they should be attenuated or abolished when contextual information is made salient regardless of its valence. If, on the other 
hand, the effects reflect the engagement of emotionally specific processes (as suggested above), they should be unaffected by this task manipulation.

\section{EXPERIMENT 2}

\section{Results}

\section{Behavioral Data}

Mean $(S D)$ valence ratings for each class of background were neutral: 0.06 (0.14); positive: 1.92 (0.27); negative: -2.12 (0.39). Ratings for both positive and negative backgrounds differed significantly from neutral background ratings (both $F>100, p<.001$ ). The difference in mean ratings between negative and neutral backgrounds was greater than that between positive and neutral backgrounds, $F(1,17)=7.144, p<.005$.

Mean recognition accuracy and RT are shown in Table 3. One-way ANOVA of hit rates showed a main effect of item type, $F(2.3,39.5)=18.51, p<.001$. Planned $t$ tests showed that there were significantly more correct responses to old items encoded with a positively valenced context than to objects associated with either negative, $t(17)=3.83, p<.005$, or neutral, $t(17)=4.95, p<.001$, backgrounds. Mean proportion of hits for objects associated with neutral and negative backgrounds did not differ reliably $(p>.1)$.

Table 3 shows mean source accuracy scores. One-way ANOVA comparing the proportion of hits attracting correct source judgments revealed a significant effect of valence, $F(1.5,25.5)=26.05, p<.001$. Planned $t$ tests showed that, compared with items encoded in a neutral context, those encoded in either negative, $t(17)=5.71$, $p<.001$ ) or positive, $t(17)=5.19, p<.001$, contexts were more likely to attract a correct source judgment. The difference between positive and negative source hit rates was not significant. ANOVA of hit RTs revealed no significant differences.

\section{Event-Related Potential Data}

The mean (range) number of trials contributing to the ERPs for each correct response type were correct rejections, 45 (17-75); neutral source hits, 19 (16-23); negative source hits, 26 (16-39); and positive source hits, 24
(16-37). For reasons discussed below, waveforms to positive and negative source hits were collapsed to form a single "emotional source hit" condition. Grand average waveforms for selected electrode sites are shown in Figure 5.

As is evident from Figure 5, waveforms began to diverge as a function of item type from about $250 \mathrm{msec}$ poststimulus. ERPs elicited by both classes of source hits (neutral and emotional) were positive relative to those elicited by correct rejections from around $300 \mathrm{msec}$; this old/new difference was initially most pronounced over left parietal and temporal regions and shifted with time as a focus developed over right frontal scalp (see Figure 6). Two additional effects are present in the ERPs to emotional source hits; from around $250 \mathrm{msec}$, a small positive shift emerges, most evident over the right posterior lateral temporal scalp, but also present at the left lateral temporal and central parietal electrodes, while from 800 msec onward, a topographically diffuse positive shift, largest over the left temporal and central scalp, is evident (see Figure 5).

ERPs were quantified by measuring mean amplitudes of the same five latency regions as in Experiment 1, and the analyses of these data proceeded along similar lines. Preliminary analyses showed no significant differences between ERPs elicited by the two classes of emotional source hit (minimum $p>.1$ ), hence the data for these item types were collapsed prior to the analyses described below. The overall ANOVA designs were the same as those used in Experiment 1. Any ANOVA demonstrating significant effects that involved item type prompted three subsidiary analyses to contrast separately neutral source hits versus correct rejections (neutral old/new effects), emotional source hits versus correct rejections (emotional old/new effects), and emotional source hits versus neutral source hits (emotion source hit effects). As in Experiment 1, additional analyses were conducted to assess between-condition differences in scalp topography.

\section{Mean Amplitude Analyses}

The outcomes of the overall ANOVAs are shown in Table 4 for each latency region. In every region, reliable effects involving the factor of item type were present.

Table 3. Mean $(S D)$ Recognition Accuracies, Source Accuracies, and RTs for Experiment 2

\begin{tabular}{|c|c|c|c|c|}
\hline & Neutral & Negative & Positive & New \\
\hline Recognition accuracy & $0.80(0.07)$ & $0.83(0.08)$ & $0.88(0.05)$ & $0.92(0.04)$ \\
\hline Proportion of correct source judgments & $0.52(0.05)$ & $0.68(0.10)$ & $0.65(0.10)$ & - \\
\hline Proportion of “don't know" judgments & $0.43(0.05)$ & $0.24(0.07)$ & $0.28(0.08)$ & $0.86(0.02)$ \\
\hline Proportion of source misattributions & $0.05(0.03)$ & $0.08(0.04)$ & $0.07(0.03)$ & $0.14(0.03)$ \\
\hline $\mathrm{RT}$ (msec) & $1204(382)$ & $1187(399)$ & $1132(277)$ & $1018(216)$ \\
\hline
\end{tabular}


Figure 5. Grand average ERP waveforms elicited by recognized items attracting correct source judgments in Experiment 2. Negative and positive source hits have been collapsed into a single set of waveforms. Sites as depicted on the insert.

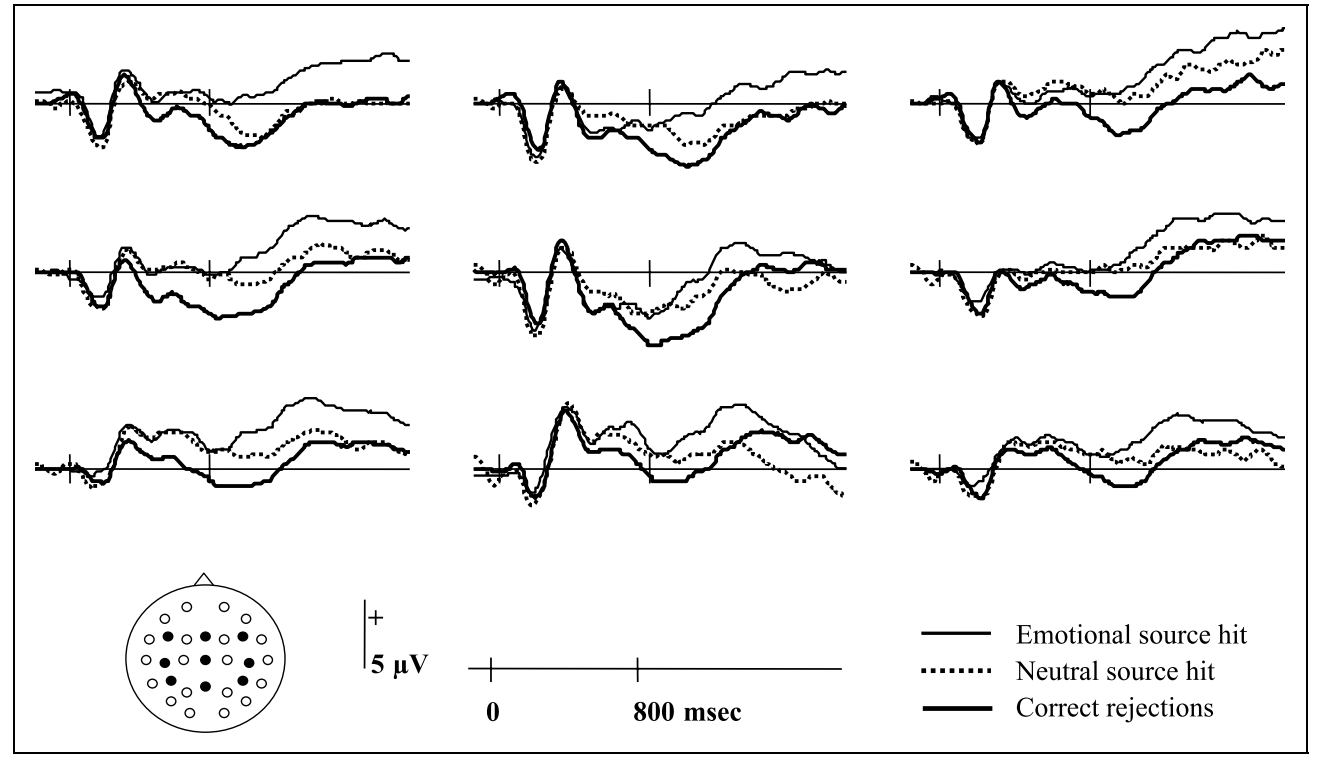

Also shown in the table are the results of the subsidiary ANOVAs for each latency region. We elucidate these below, discussing the neutral old/new effects, emotional old/new effects and emotional source hit effects, respectively.

Neutral old/new effects. As shown in Table 4, a main effect of item type was found for the first 4 latency regions, reflecting in each case a greater positivity for ERPs to neutral source hits. The interactions found for all analyzed latency regions among item type, hemisphere, and AP location reflect the fact that the old/new effects were distributed unevenly over the scalp in each case. As can be seen in Figure 6, these effects are left lateralized early in the epoch, but demonstrate a pronounced right frontal maximum subsequently.

Emotional old/new effects. A main effect of item type was accompanied by interactions with the factors of hemisphere and AP location in all latency regions analyzed. For the 300- to 500-msec and 500- to $800-\mathrm{msec}$ regions, these interactions reflect the greater size of the old/new effects over the left temporo-parietal scalp. In the subsequent latency regions, these effects are joined
Figure 6. Spherical spline maps showing scalp distributions of the old/ new effects associated with items attracting correct source judgments in the neutral (A) and emotional (B) conditions in the latency regions shown. Each map is proportionately scaled between the extremes of the depicted effect (values in each case are given in microvolts)

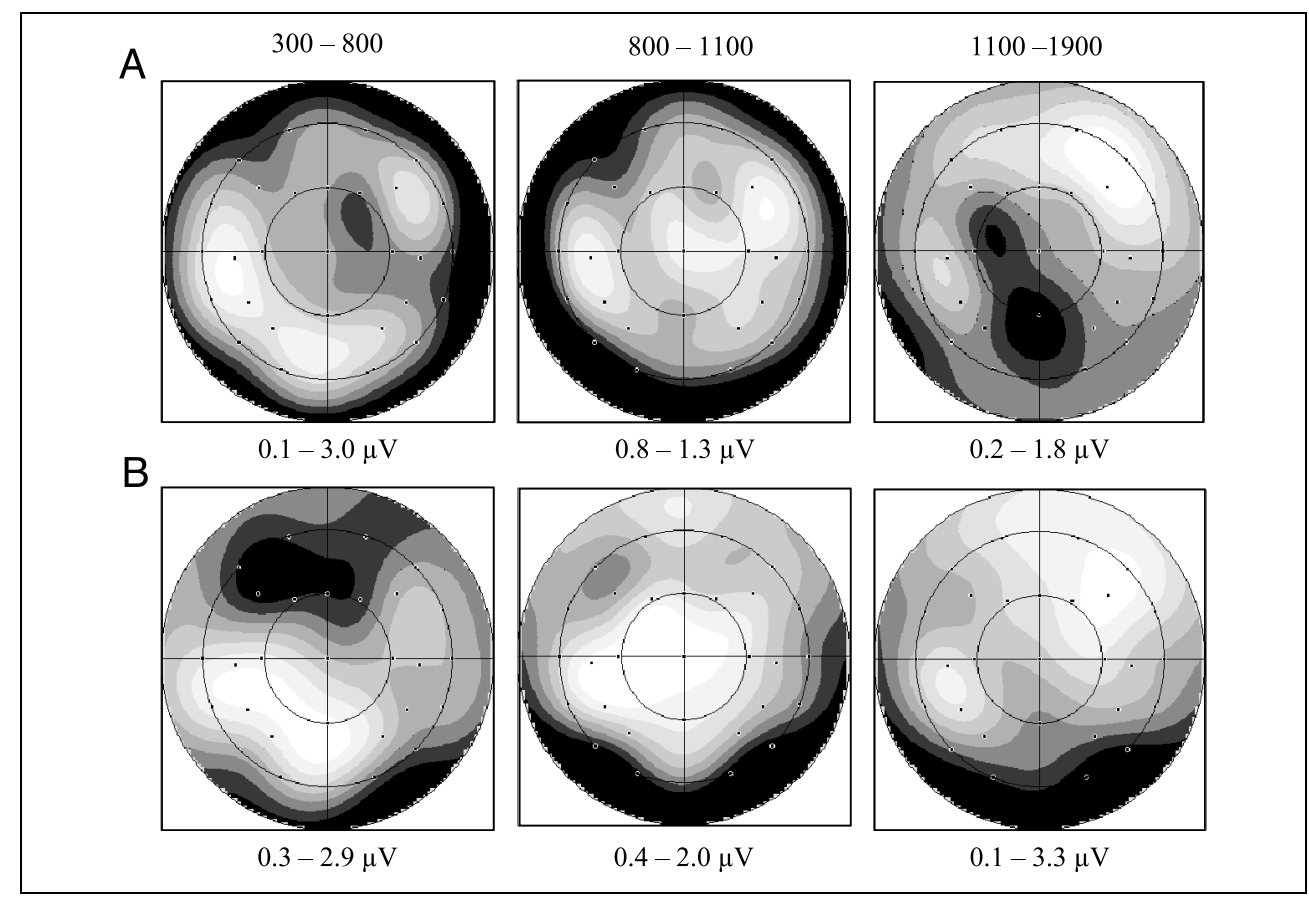




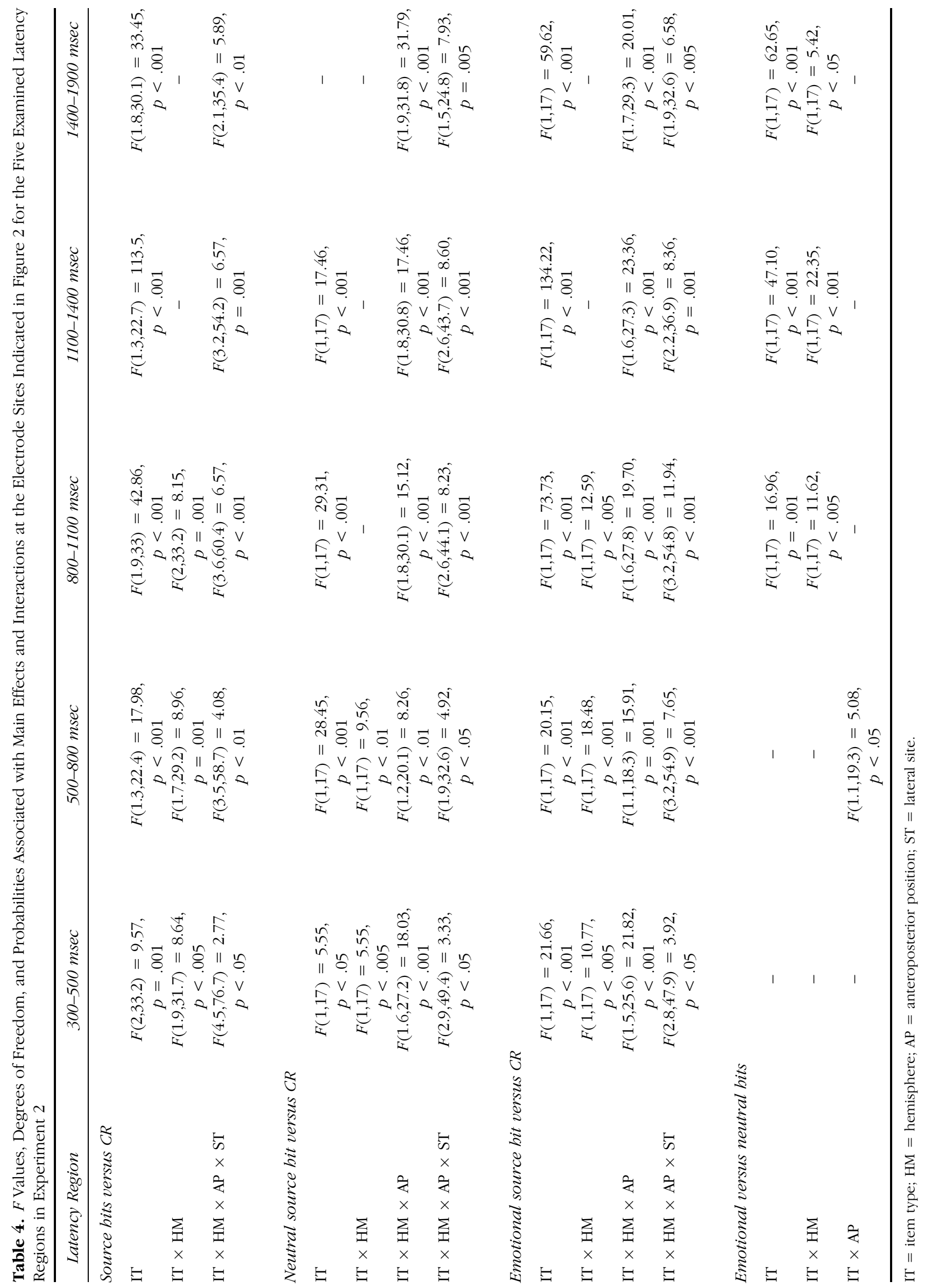


by a second maximum over the right fronto-temporal scalp (see Figure 6).

Emotion effects. In contrast with Experiment 1, emotion effects in the 300- to 500-msec latency region failed to reach significance in the ANOVA utilizing the 18 lateral sites selected a priori. However, an ANOVA on data from temporal/central and parietal electrodes revealed a main effect of item type, $F(1,17)=5.07, p<.05$. Emotion effects were also present in the 500- to 800-msec latency region, in the form of an interaction of item type with AP position. There was a small, but significant, difference in amplitude most evident at right lateral sites, with emotional source hits being more positive-going than neutral source hits at right lateral parietal and temporal sites, but not at right frontal sites [Item Type $\times$ AP interaction, $F(1.2,20.8)=4.35, p<.05]$. Apparent amplitude differences at midline sites in this latency region were not significant. In the 800 - to $1100-\mathrm{msec}$ latency region, the large differences between waveforms were reflected in a main effect of item type, with emotional source hits eliciting the more positive-going waveforms. The emotion effects remained significant until the end of the recording epoch. In the latter three latency regions (800-1100, 1100-1400, and 1400-1900 msec), the item type effects interacted with hemisphere, reflecting their tendency to be left lateralized (see Figure 7). It should be noted that the pattern of results over right frontal scalp in these latency regions suggest that the emotional effects were additive with the right frontal effect, but did not modulate this effect itself.

\section{Topographic Analyses}

An initial ANOVA, employing the factors of site, the five latency regions, and emotion, contrasted the scalp distributions of the old/new effects elicited by each class of source hit (see Figure 6). The ANOVA revealed a significant interaction between all three factors, $F(6.2,104.7)=$ 2.82, $p<.05$. Subsidiary ANOVAs, conducted separately on the data from each latency region, revealed no signif- icant differences in scalp topography prior to $1100 \mathrm{msec}$ poststimulus. As revealed by item type by electrode site interactions, the topographies of the two effects differed thereafter, $F(4.3,73.2)=9.18, p<.001$, and $F(3.5,59)=$ $7.04, p<.001$, for the $1100-$ to $1400-\mathrm{msec}$ and $1400-$ to 1900-msec latency regions, respectively.

A second set of subsidiary ANOVAs examined the topographies of the neutral and emotional old/ new effects separately as a function of latency region. Consistent with the analyses of the raw amplitude data, both ANOVAs revealed significant interactions between electrode site and latency region, reflecting in each case a shift with time from a left temporo-parietal toward a right frontal maximum [neutral: $F(5.9,100.1)=3.38$, $p=.005$; emotional: $F(5.7,96.5)=8.46, p<.001$, respectively].

\section{Additional Analyses Across Experiments}

While the late-onset effects of emotion were large and robust in each experiment, the early (300-500 msec) effects were small in amplitude and only weakly significant. To characterize these effects further, the data from the 300- to 500-msec latency region were analyzed across experiments, employing the factors of experiment, item type, hemisphere, AP position, and lateral site. An initial ANOVA, employing data from the same 18 lateral electrode sites used previously revealed a significant interaction among item type, hemisphere, AP position, and lateral site, $F(2.3,78.3)=4.37, p<.05$. A subsidiary ANOVA was conducted on the four electrode sites where the effects appeared largest (the anterior and posterior lateral temporal sites in each hemisphere), revealing a main effect of item type, $F(1,34)=13.6, p=.001$, indicating a highly reliable effect of emotion at these sites across the two experiments. The waveforms from the right posterior lateral temporal site, at which the effect is clearest, are shown in Figure 8, collapsed across the two experiments. Figure 8 also illustrates that the onset of emotion effects precedes the left parietal old/new effect.
Figure 7. Spherical spline maps showing the scalp distributions of the emotion effect from Experiment 2 in the latency regions shown. Each map is proportionately scaled between the extremes of the depicted effect (values in each case are given in microvolts).

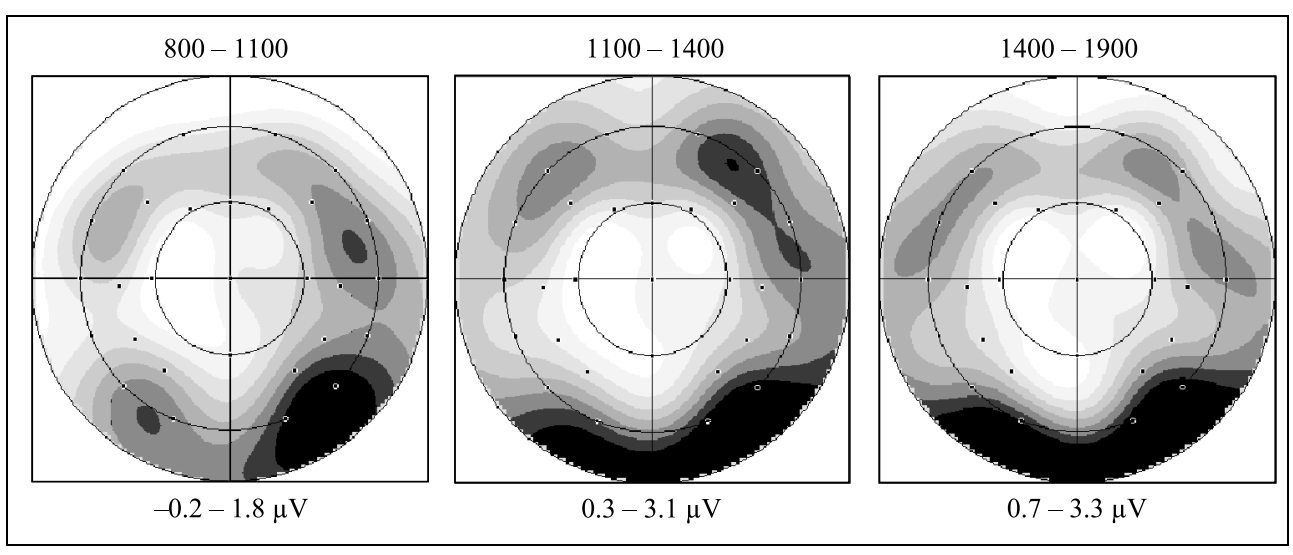




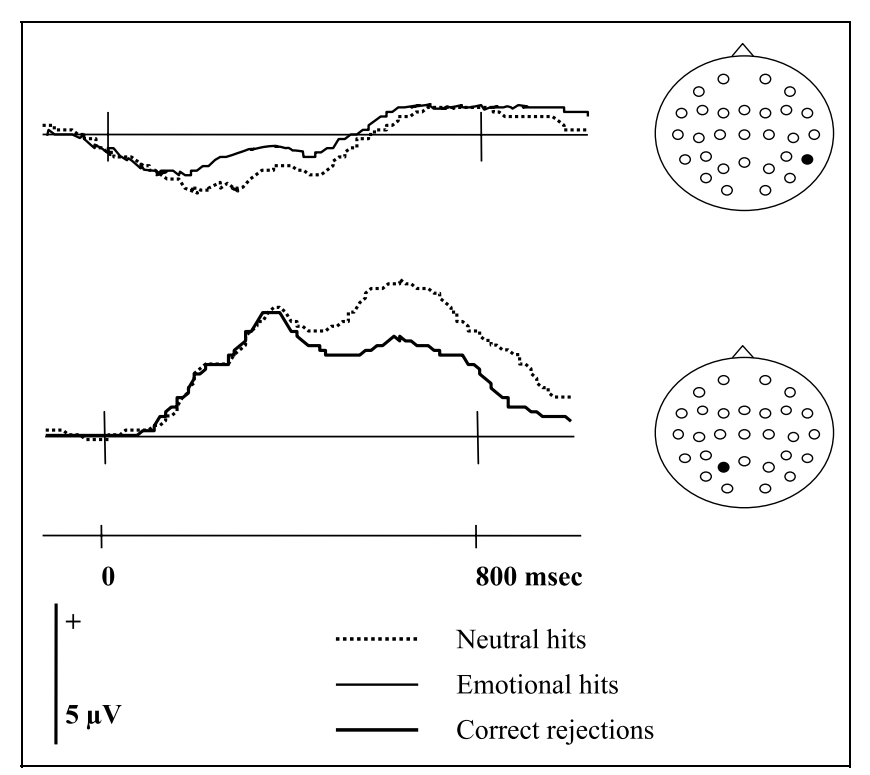

Figure 8. Grand average ERP waveforms from right posterior temporal and left parietal sites collapsed across experiment 1 and 2 .

\section{Discussion}

\section{Behavioral Data}

As was observed in Experiment 1, items encoded in positive contexts were recognized at a slightly, but significantly, higher level of accuracy than those encoded in either negative or neutral contexts. Thus, in the present paradigm, association of a neutral cue with a positively valenced context leads consistently to a small but robust enhancement of recognition memory. The findings from both the present experiment and Experiment 1 are consistent with previous reports suggesting that recognition memory is modulated by emotion (Maratos \& Rugg, 2001: Experiment 2; Tabert et al., 2001; but see Danion, Kauffmann-Muller, Grange, Zimmermann, \& Greth, 1995; Maratos \& Rugg, 2001: Experiment 1, for negative findings). It is, however, unclear why these findings were confined to items encoded in positive contexts. One possibility is that subjects were more likely to fail to encode objects associated with negative contexts because of the extreme, "attention-grabbing" nature of some of the scenes forming these contexts.

In contrast with the findings for item recognition, those for the subsequent source judgment were unequivocal in supporting the proposal that episodic memory is enhanced for emotional events (see Christianson, 1992). Items associated with both positive and negative contexts were associated with a greater proportion of accurate source judgments than were items encoded in neutral contexts. The possibility that this finding merely reflects a response bias in favor of the "emotional" sources can be discounted on two grounds. As shown in Table 3, the overriding majority of false alarm trials (when subjects misclassified new pictures as old) were given a "don't know" response, rather than an emotional source endorsement. Furthermore, the majority of source errors for correctly recognized neutral items were also in the "don't know" category rather than in the form of a source misattribution. Together, these findings suggest strongly that the greater accuracy for emotional versus neutral source judgments cannot be explained by a bias in favor of the emotional response categories.

\section{Event-Related Potential Data}

The present findings were in many respects similar to those obtained in Experiment 1. Thus, a small, early (ca. $300 \mathrm{msec}$ ) emotion effect was evident at lateral temporal sites, whereas the following left parietal old/new effect failed to differentiate neutral from emotional hits. Subsequent to the left parietal effect, however, emotional hits elicited a sustained positivity, which persisted until the end of the recording epoch. Thus, in contrast with the findings of Maratos and Rugg (2001), the requirement explicitly to attend to retrieved contextual information did not eliminate the emotion effects observed during yes/no recognition. It therefore seems unlikely that the effects observed in the first experiment merely reflect the greater salience of incidentally retrieved emotional contextual information. It does, however, remain possible that the greater memorability of emotional contexts led to differences in recollection between items encoded in emotional and neutral contexts that were not fully eliminated by the inclusion of the "don't know" response option for the source judgment. It would be of interest to use an index such as confidence level to further segregate emotional and neutral source hits. ${ }^{2}$ It is worth noting, however, that previous studies suggest that the principal ERP effect indexing the amount of source information recollected is the left parietal old/new effect (Wilding, 2000), which was not significantly different between emotional and neutral source hits.

The findings in the present experiment differ from those in experiment one in that both neutral and emotional hits elicited sizeable right frontal old/new effects. As noted in the Introduction, right frontal effects have frequently been reported in ERP studies of source memory, and have been interpreted as a reflection of the engagement of postretrieval monitoring operations (e.g., Rugg, Otten, \& Henson, 2002). The emergence of these effects in the present experiment, but not in Experiment 1, presumably reflects the greater demands placed upon such operations by the need explicitly to evaluate the content of retrieved episodic information (Rugg et al., 2002; Senkfor \& Van Petten, 1998). As was the case in Experiment 2 of Maratos and Rugg (2001), which also employed a source memory task, the present right frontal old/new effects did not differ according to the emotional status of the test items. This finding 
has implications for the proposal that the late-onset emotion effects observed here reflect the engagement of emotion- specific processes akin to those reflected by the "LPP" reported in studies investigating ERPs elicited by emotional and neutral pictures (Dolcos \& Cabeza, 2002; Keil et al., 2002; Cuthbert et al., 2000; Schupp et al., 2000; Palomba, Angrilli, \& Mini, 1997; Mini, Palomba, Angrilli, \& Bravi, 1996). It is generally held that the cognitive operations reflected by the right frontal effect (which in this experiment co-occurred with the emotion effects) are attentionally demanding, in as much they involve the conscious evaluation of the contents of retrieval (e.g., Rugg et al., 2002; Van Petten, Luka, Rubin, \& Ryan, 2002; Curran, Schacter, Johnson, \& Spinks, 2001). However, as noted previously, the LPP has been proposed to reflect enhanced attentional processing of emotional stimuli (Lang et al., 1998). If both of these proposals are correct, it would appear that the cooccurrence of the right frontal and emotion-specific effects signifies that subjects were able to divide their attentional resources between two kinds of "postretrieval" operation - one generic (reflected in the right frontal effect) and one emotionally specific (reflected in the LPP). An alternative possibility is that the emotion effects reflect processes that operate independently of attention.

\section{GENERAL DISCUSSION}

In both experiments, old items elicited robust "generic" old/new effects, that is, effects reported previously in studies employing exclusively neutral material (see Friedman \& Johnson, 2000; Rugg \& Allan, 2000, for reviews). These effects were insensitive to the items' study history. In Experiment 1, the left parietal old/new effect was evident for both neutral and emotional items, and in Experiment 2, this effect was accompanied by a right frontal effect. On the assumption that the magnitude of the left parietal effect is proportional to the amount of episodic information recollected about an event (Wilding, 2000; Rugg, Cox, Doyle, \& Wells, 1995), the equivalent amplitude of the neutral and emotional effects in the two experiments implies that the informational content of the two classes of study episode was similar. Likewise, the equivalent right frontal effects elicited by the two classes of hit in Experiment 2 suggest that postretrieval monitoring was engaged to a similar extent regardless of the emotional valence of the retrieved episodic information. Thus, as in Maratos and Rugg's (2001) work, the present findings indicate that the retrieval of neutral and emotional episodic information in response to an ostensibly neutral retrieval cue engages a common set of retrieval mechanisms.

In striking contrast with Maratos and Rugg (2001) however, the present findings suggest strongly that items associated with emotional study contexts also engage retrieval processes that are qualitatively distinct from those engaged by items studied in neutral contexts. The most likely reason for these disparate findings is the employment of different stimulus materials (pictorial vs. verbal). As was noted in the Introduction, it is plausible to suppose that, other things being equal, emotional information depicted pictorially has greater salience than that conveyed verbally.

The earliest difference between the ERPs elicited by emotional and neutral hits took the form of a small positive shift in the waveforms elicited by the former items. This shift was maximal over the lateral posterior temporal scalp and onset more than $100 \mathrm{msec}$ prior to the onset of the left parietal old/new effect (see Figure 8). One possibility is that objects associated with emotional contexts acquired some of the emotional attributes of these contexts, and thus elicited neural activity at test that differed from the activity elicited by objects paired with neutral backgrounds. In support of this proposal, it has been reported that one ERP effect elicited by emotional pictures from the IAPS is a positivity relative to ERPs elicited by neutral pictures with an onset around $300 \mathrm{msec}$ poststimulus over the posterior scalp (Keil et al., 2002; Cuthbert et al., 2000; Schupp et al., 2000). Together with complementary fMRI findings (Vuilleumier, Armony, Driver, \& Dolan, 2001; Lang et al., 1998), these ERP results have been taken to suggest that emotional pictures modulate activity in early and higher visual regions (Keil et al., 2002). The scalp distribution of these earlier effects is more widespread and posterior to the distribution of effects in the current study, and it is possible that the present effects reflected activity in a subset of the generators responsible for the emotion effects reported in previous studies, and may have arisen not only because the items acted as cues for the retrieval of emotional versus neutral study episodes, but also because of emotional attributes that had become inherent to the objects themselves, at least temporarily.

In both experiments, late-onset (ca. $700 \mathrm{msec}$ ) emotion effects took the form of a sizeable, temporally extended positivity, the scalp distribution of which was distinct from that of the neutral old/new effects. Initially, this positivity was maximal over the left temporo-central scalp, but shifted in distribution with time, implying the involvement of multiple generator populations. Whereas the comparison of Figures 4 and 7 suggests that the scalp topographies of the effects in the two experiments may differ, an across-experiment ANOVA did not reveal evidence in support of this, $F(4.5,153)=1.66, p>.1$.

As already noted, an "LPP" has previously been reported to differentiate emotional and neutral pictures from the IAPS set (Dolcos \& Cabeza, 2002; Keil et al., 2002; Cuthbert et al., 2000; Schupp et al., 2000; Palomba et al., 1997; Mini et al., 1996). Thus, a parsimonious explanation for the effects observed in the present experiments is that similar processes are engaged by 
emotionally valenced perceptual representations whether they are sensory or mnemonic in origin. Small differences in distribution and latency may reflect direct versus indirect conveyance of the emotional information in these scenarios.

In both experiments, the ERPs elicited by items associated with the positively and negatively valenced context hits were essentially identical. This finding might be thought surprising in light of evidence that different emotions are subserved by neural systems that are at least partially distinct (see Calder et al., 2001, for a review). However, the present findings are not without precedence. Whereas differences in ERPs elicited by positive and negative stimuli have been reported (Dolcos \& Cabeza, 2002; Cuthbert et al., 2000), these were small in relation to the differences between each stimulus class and neutral items. Moreover, such valencespecific effects were not detected in other studies employing similar materials (e.g., Schupp et al., 2000; Palomba et al., 1997; Mini et al., 1996).

Finally, we note that, in discussing our own and others' findings, we have assumed that ERP emotion effects do indeed reflect the affective qualities of emotional versus neutral experimental material. We acknowledge however the possibility that ERP emotion effects are due not to emotionality, but to some confounding attribute such as "interest" (e.g., Hamann, Ely, Grafton, \& Kilts, 1999), confidence, or semantic relatedness (Maratos et al., 2000; Phelps et al., 1998). Resolution of this issue will require the employment of stimulus materials that have been carefully calibrated in respect of these and other potentially confounding attributes.

\section{METHODS}

\section{General Methods}

We describe below those aspects of the methods that were common to Experiments 1 and 2. Both experiments conformed to a type approved by an institutional ethics committee.

\section{Stimulus Materials}

Stimuli consisted of two picture components, an object superimposed on a background context. Objects were presented within a yellow box to clearly demarcate their separation from the background. Backgrounds were drawn principally from the IAPS (Lang et al., 1997), a series of pictures with standardized ratings for valence and arousal. About 5\% of the background materials consisted of photographs additional to the IAPS set. A subset of the pool of backgrounds were selected based on pilot studies carried out using 12 British subjects (6 women, mean age 22.4 years), who assessed valence and arousal of all materials using separate five-point Likert scales. For a small number of pictures, the ratings of these subjects differed significantly from the IAPS norms. These items were excluded, as were those which showed across subject variances in rating scores greater than .75 .

The selected set of backgrounds consisted of 180 pictures, subdivided into three sets, which were negatively (mean 1.29 , SD 0.47), neutrally (mean 3.06, SD 0.43), or positively (mean 4.17, $S D$ 0.54) emotionally valenced as determined by the ratings of the pilot group described previously. None of the backgrounds contained sexual material. The objects that were superimposed on the selected backgrounds came from a wide range of semantic categories (e.g., tools, furniture, clothing, machinery). These items were assessed for emotional arousal and valence by the same subjects who rated the backgrounds. Objects that deviated from neutral valence (valence mean $<2.75$ or $>3.25$; variance $>0.75$ ) or were arousing (mean arousal rating $>1.5$ ) were excluded. A total of 360 objects were employed as critical stimuli.

\section{List Construction}

At study, subjects studied one of six study lists. Each list included the 180 selected backgrounds, arranged pseudo-randomly, with no more than three pictures from the same valence category presented consecutively. Each critical object was paired with a neutral background in one list, a negative background in another, a positive background in a third, and was available as a new item for the remaining three lists. The study phase was separated into three parts to allow rest breaks, and the first two background/object pairs in each part were neutral filler items. Therefore, each study list consisted of 186 background/object pairs (including the fillers). Each study list had three related study lists, consisting of 180 old items, 90 new items, and 6 fillers. Each test list utilized a different set of new items, and each subject would be tested on one of the three test lists. A practice study list of six background/object pairs and a practice test list of nine objects were also constructed and were used to train subjects prior to the experiment proper.

\section{Study Procedure}

In the study phase, stimuli were presented in the center of a color computer monitor. The background was initially presented alone on the screen for $3 \mathrm{sec}$. During this time subjects made a verbal rating of the background's emotional valence. In the first experiment a five-point Likert scale was utilized, ranging from -2 (very unpleasant) to +2 (very pleasant). In the second experiment a seven-point scale $(-3$ to +3$)$ was employed in an effort to improve sensitivity.

Three seconds after presentation of the context, the critical object was superimposed centrally upon the background, and subjects were required to imagine a 
connection between background and object. The connection was made covertly. The object and background were presented together for $5 \mathrm{sec}$, and the screen was then blanked for $750 \mathrm{msec}$ before presentation of the next background. Six practice trials were given prior to the study proper, during which the subjects were required to describe verbally the connections they had made between background and object, thereby ensuring they understood the task. During the study phase proper, rest breaks were given after every 62 trials, the first two trials of each of the subphases being fillers.

\section{Event-Related Potential Recording and Analysis}

Electroencephalograph (EEG) was recorded from $31 \mathrm{Ag}$ / $\mathrm{AgCl}$ electrodes. Twenty-nine of these were embedded in an elasticated cap (Falk Minow Services "Easycap," www.easycap.de/easycap; Montage depicted in Figure 2) and one was attached to each mastoid process. Recordings were made with reference to $\mathrm{Fz}$ and subsequently rereferenced to linked mastoids. Vertical and horizontal electro-oculographs (EOG) were recorded from electrode pairs above and below the right eye and on the lateral canthi. EEG and EOG were amplified with a bandwidth of $0.03-30 \mathrm{~Hz}$ (3 dB points) and digitized (12 bit) at a rate of $125 \mathrm{~Hz}$.

The recording epochs began $104 \mathrm{msec}$ prior to stimulus onset and had a duration of $2048 \mathrm{msec}$. A correction procedure was used to minimize the number of trials rejected due to blink artifacts. The method was similar to methods employed previously (Rugg, Mark, Gilchrist, \& Roberts, 1997), using linear regression to estimate and correct the contribution of blink artifact to the scalp EEG. Trials containing nonblink vertical eye movements or horizontal eye movements were rejected. Trials where A/D saturation occurred or baseline drift exceeded $\pm 40 A \mathrm{~V}$ were also rejected.

ERPs were formed for correctly rejected new items and correctly recognized old items associated with each valence category (positive, negative, and neutral). In Experiment 2, the classes of recognized old items were further separated based on whether correct source judgments were made. Waveforms were digitally smoothed with a zero-phase shift low pass filter $(3 \mathrm{~dB}$ down at $19.4 \mathrm{~Hz}$ ). Subjects were excluded if the number of trials contributing to any ERP waveform of experimental interest fell below 16 trials.

\section{Experiment 1}

Subjects

Twenty-four right-handed young adults (age range 18-32 years, mean 24.5) were employed as subjects and remunerated at the rate of $\$ 7.50 / \mathrm{hr}$. All reported themselves to be in good health with no history of neurological or psychiatric illness. Six subjects were excluded from the final analysis, two due to inadequate behavioral performance and four due to insufficient trials in critical conditions. Of the 18 subjects contributing data, 6 were women.

\section{Test Procedure}

The test phase followed the study phase after a delay of around $5 \mathrm{~min}$, during which a serial subtraction task was used to prevent rehearsal. A white asterisk was presented against a black background for $500 \mathrm{msec}$, following which the stimulus was presented for a duration of 750 msec; a white fixation cross on a black background was presented for $1750 \mathrm{msec}$ before presentation of an asterisk denoted the imminent onset of a new trial, giving a stimulus onset asynchrony of $3 \mathrm{sec}$.

Subjects viewed the stimuli while resting each forefinger on a microswitch. They were instructed to respond with one finger when the object depicted had been presented in the preceding study phase, and with the other finger if it was being viewed for the first time. Assignment of responses to fingers was counterbalanced across subjects. Instructions were to respond as quickly as possible without sacrificing accuracy. Rest breaks were given after every 92 stimuli, with the first two stimuli of each subphase being filler items. Prior to the test phase proper, an example test phase was given, containing the six items from the study example, plus three new items. None of these items appeared in the subsequent test list.

\section{Experiment 2}

Subjects

Nineteen right-handed young adults (age range 1833 years, mean 23.2) were employed as subjects and remunerated at the rate of $\$ 7.50 / \mathrm{hr}$. All reported themselves to be in good health with no history of neurological or psychiatric illness. One subject was excluded from the final analysis due to inadequate behavioral performance. Of the 18 subjects contributing data, 11 were women.

\section{Test Procedure}

As with Experiment 1, the test phase followed the study phase after a delay of $5 \mathrm{~min}$, a serial subtraction task again being employed to prevent rehearsal. A white asterisk was presented against a black background for $500 \mathrm{msec}$, following which the stimulus was presented for $750 \mathrm{msec}$. Subjects had to make an old/new response judgment as quickly and accurately as possible as described in Experiment 1.

The screen was blank for 750 msec after stimulus offset, after which a question mark character was displayed for 2 sec to cue the second, source response. The requirement was to indicate which encoding context the item had been associated with at study. Subjects per- 
formed this task with the forefinger and middle finger of each hand resting on separate microswitches. These switches were used to indicate whether the object had been seen in a "negative," "neutral," or "positive" context, or to signal that the context with which an object had been presented could not be remembered ("don't know" responses). The finger required for each judgment was rotated across subjects. Between each trial, a white fixation cross on a black background appeared for $1000 \mathrm{msec}$, giving a stimulus onset asynchrony of 5 sec.

\section{Acknowledgments}

M. D. R. and this research were supported by the Wellcome Trust and a Medical Research Council Cooperative Grant.

Reprint requests should be sent to Adam P. R. Smith, Institute of Cognitive Neuroscience, University College London, 17 Queen Square, London WC1N 3AR, UK, or via e-mail: adam.smith@ucl.ac.uk.

\section{Notes}

1. Most functional imaging studies of emotional retrieval have utilized emotional material as retrieval cues. Such designs do not allow unequivocal separation of effects due to emotional memory retrieval from those due to on-line processing of the presented material. Manipulation of the context in which a neutral item is encoded allows retrieval of emotional memory to be examined while holding the emotional valence of the retrieval cue constant.

2. We thank an anonymous referee for suggesting this possibility.

\section{REFERENCES}

Adolphs, R., Tranel, D., \& Denburg, N. (2000). Impaired emotional declarative memory following unilateral amygdala damage. Learning and Memory, 7, 180-186.

Cacioppo, J. T., Crites, S. L., \& Gardner, W. L. (1996). Attitudes to the right: Evaluative processing is associated with lateralized late positive event-related brain potentials. Personality and Social Psychology Bulletin, 22, 1205-1219.

Cahill, L., \& McGaugh, J. L. (1998). Mechanisms of emotional arousal and lasting declarative memory. Trends in Neuroscience, 21, 294-299.

Calder, A. J., Lawrence, A. D., \& Young, A. W. (2001). Neuropsychology of fear and loathing. Nature Reviews Neuroscience, 2, 352-363.

Christianson, S. A. (1992). The handbook of emotion and memory. Hillsdale, NJ: Erlbaum.

Curran, T., Schacter, D. L., Johnson, M. K., \& Spinks, R. (2001). Brain potentials reflect behavioral differences in true and false recognition. Journal of Cognitive Neuroscience, 13, 201-216.

Cuthbert, B. N., Schupp, H. T., Bradley, M. M., Birbaumer, N., \& Lang, P. J. (2000). Brain potentials in affective picture processing: Covariation with autonomic arousal and affective report. Biological Psychology, 52, 95-111.

Danion, J. M., Kauffmann-Muller, F., Grange, D., Zimmermann, M. A., \& Greth, P. (1995). Affective valence of words, explicit and implicit memory in clinical depression. Journal of Affective Disorders, 34, 227-234.
Dolan, R. J., Lane, R., Chua, P., \& Fletcher, P. (2000). Dissociable temporal lobe activations during emotional episodic memory retrieval. Neuroimage, 11, 203-209.

Dolcos, F., \& Cabeza, R. (2002). Event-related potentials of emotional memory: Encoding pleasant, unpleasant, and neutral pictures. Cognitive, Affective and Behavioral Neuroscience, 2, 252-263.

Friedman, D., \& Johnson, R., Jr. (2000). Event-related potential (ERP) studies of memory encoding and retrieval: A selective review. Microscopy Research and Technique, 51, 6-28.

Hamann, S. B., Ely, T. D., Grafton, S. T., \& Kilts, C. D. (1999). Amygdala activity related to enhanced memory for pleasant and aversive stimuli. Nature Neuroscience, 2, 289-293.

Keil, A., Bradley, M. M., Hauk, O., Rockstroh, B., Elbert, T., \& Lang, P. J. (2002). Large-scale neural correlates of affective picture processing. Psychophysiology, 39, 641-649.

Lang, P. J., Bradley, M. M., \& Cuthbert, B. N. (1997). The International Affective Picture System (IAPS): Photographic slides. Gainesville, FL: University of Florida.

Lang, P. J., Bradley, M. M., Fitzsimmons, J. R., Cuthbert, B. N., Scott, J. D., Moulder, B., \& Nangia, V. (1998). Emotional arousal and activation of the visual cortex: An fMRI analysis Psychophysiology, 35, 199-210.

Maratos, E. J., Dolan, R. J., Morris, J. S., Henson, R. N., \& Rugg, M. D. (2001). Neural activity associated with episodic memory for emotional context. Neuropsychologia, 39, 910-920.

Maratos, E. J., \& Rugg, M. D. (2001). Electrophysiological correlates of the retrieval of emotional and non-emotional context. Journal of Cognitive Neuroscience, 13, 877-891.

McCarthy, G., \& Wood, C. C. (1985). Scalp distributions of event-related potentials: An ambiguity associated with analysis of variance models. Electroencephalography and Clinical Neurophysiology, 62, 203-208.

Mini, A., Palomba, D., Angrilli, A., \& Bravi, S. (1996). Emotional information processing and visual evoked brain potentials. Perception and Motor Skills, 83, 143-152.

Palomba, D., Angrilli, A., \& Mini, A. (1997). Visual evoked potentials, heart rate responses and memory to emotional pictorial stimuli. International Journal Psychophysiology, 27, 55-67.

Phelps, E. A., LaBar, K. S., Anderson, A. K., O'Connor, K. J., Fulbright, R. K., \& Spencer, D. D. (1998). Specifying the contributions of the human amygdala to emotional memory: A case study. Neurocase, 4, 527-540.

Rugg, M. D., \& Allan, K. (2000). Memory retrieval: An electrophysiological perspective. In M. S. Gazzaniga (Ed.), The new cognitive neurosciences (2nd ed., pp. 805-816). Cambridge: MIT Press.

Rugg, M. D., Cox, C. J., Doyle, M. C., \& Wells, T. (1995). Event-related potentials and the recollection of low and high frequency words. Neuropsychologia, 33, 471-484.

Rugg, M. D., Mark, R. E., Walla, P., Schloerscheidt, A. M., Birch, C. S., \& Allan, K. (1998). Dissociation of the neural correlates of implicit and explicit memory. Nature, 392, 595-598.

Rugg, M. D., Mark, R. E., Gilchrist, J., \& Roberts, R. C. (1997). ERP repetition effects in indirect and direct tasks: Effects of age and inter-item lag. Psychophysiology, 34, 572-586.

Rugg, M. D., Otten, L. J., \& Henson, R. N. A. (2002). The neural basis of episodic memory: Evidence from functional neuroimaging. Philosophical Transactions of the Royal Society of London, B Biological Sciences, 357, 1097-1110.

Rugg, M. D., Schloerscheidt, A. M., Doyle, M. C., Cox, C. J., \& Patching, G. R. (1996). Event-related potentials and the 
recollection of associative information. Brain Research, Cognitive Brain Research, 4, 297-304.

Schupp, H. T., Cuthbert, B. N., Bradley, M. M., Cacioppo, J. T., Ito, T., \& Lang, P. J. (2000). Affective picture processing: The late positive potential is modulated by motivational relevance. Psychophysiology, 37, 257-261.

Senkfor, A. J., \& Van Petten, C. (1998). Who said what? An event-related potential investigation of source and item memory. Journal of Experimental Psychology Learning Memory and Cognition, 24, 1005-1025.

Smith, M. E. (1993). Neurophysiological manifestations of recollective experience during recognition memory judgements. Journal of Cognitive Neuroscience, 5, 1-13.

Tabert, M. H., Borod, J. C., Tang, C. Y., Lange, G., Wei, T. C., Johnson, R., Nusbaum, A. O., \& Buchsbaum, M. S. (2001). Differential amygdala activation during emotional decision and recognition memory tasks using unpleasant words: An fMRI study. Neuropsychologia, 39, 556-573.

Van Petten, C., Luka, B. J., Rubin, S. R., \& Ryan, J. P. (2002). Frontal brain activity predicts individual performance in an associative memory exclusion test. Cerebral Cortex, 12, 1180-1192.

Vuilleumier, P., Armony, J. L., Driver, J., \& Dolan, R. J. (2001). Effects of attention and emotion on face processing in the human brain: An event-related fMRI study. Neuron, 30, 829-841.

Wilding, E. L. (2000). In what way does parietal ERP old/new effect index recollection? International Journal of Psychophysiology, 35, 81-87.

Wilding, E. L., \& Rugg, M. D. (1996). An event-related potential study of recognition memory with and without retrieval of source. Brain, 119, 889-905. 